\title{
A Decision Support System for the Selection of Best Procurement System in Construction
}

\author{
Shiyamini Ratnasabapathy, Raufdeen Rameezdeen
}

\begin{abstract}
The procurement system is a key means through which the client creates pre-conditions for successful achievement of project specific objectives. Wrong selection of procurement system generally leads to project failure and client dissatisfaction. Therefore, a systematic and realistic approach for the selection of the best procurement system is critical to the success of any project to achieve the clients' ultimate goals. As far as Sri Lankan construction industry is concerned, the practice of procurement selection is rather unstructured and ad hoc. Therefore, a realistic and consistent approach is essential to aid the clients in selecting the most appropriate procurement system. This paper presents a Decision Support System developed for the procurement selection based on Multi Attribute Utility Technique. Four rounds of Delphi surveys were carried out to investigate the most significant factors and their level of influence on various construction procurement systems. From the third and fourth round of Delphi, utility values for each factor against various procurement systems were derived. Based on decisive factors and the utility values derived form the survey, a multi-criteria model was developed. The special feature of the model is the inclusion of a set of exclusive selection criteria at macro level and wide range of various procurement options. The outcome of the model was evaluated for its applicability and efficiency with the use of multiple case studies and an expert opinion survey. Finally, the evaluated model was further enhanced to a Decision Support System. The model has the potential to assist the clients/their consultants and it seeks to overcome any inconsistency in the effective decision making process.
\end{abstract}

\section{Introduction}

The construction industry is one of the backbones of the economy of many countries. Industry-wide studies on the performance of the construction industry (NWPC, 1990; Latham, 1994; Egan, 1998) have pointed to some key improvement areas, one of which is the use of an appropriate procurement method. Since the construction procurement determines the overall framework and structure of responsibilities and authorities for participants within the construction process, it is a key factor which contributes to achieve the overall strategic goals of the client and project success. The selection process of procurement systems has become increasingly complex, mainly as a result of the continuing proliferation of alternative methods for procuring building projects, their ever increasing technical complexity and clients' continuing desire for speedy commencement and completion, all of which have led to the demand for more sophisticated methods of selection being devised. In addition, due to fragmented and complex nature of construction projects, there is no fixed metod of dealing with procurement, as often they are different in scale, complexity and nature. In choosing which procurement system to apply, there is a need to take into consideration various factors from the internal and external environment in the operatinal area of the project and industry. A variety of factors have to be taken into account before any practical decisions can be made. Several researchers have strived to develop a systematic approach for procurement system selection (NEDO
1985; Skitmore and Mardson, 1988; Masterman, 1992; Chan et.al., 2001; Cheung et.al., 2001; Luu et.al., 2003). Among the various models, Multi Attribute Utility Technique (MAUT) has received the greatest attention.

The Sri Lankan construction industry has not developed in quite the same way as that of other developing countries during the past decades. The current review of the trends of project procurement systems used in Sri Lanka reveal that the Measure and Pay is the dominant system and usage of alternative procurement system is underprivileged compared to other developing countries. The popularity of Measure and Pay is mainly due to the Government influence on the construction industry of Sri Lanka. As a major client and the regulator, the Government has not taken initiative for the development of alternative procurement methods (Shiyamini et al, 2005). In addition, the practice of procurement selection is rather unstructured and ad hoc. There is no systematic and realistic approach used to select an appropriate system for a particular project. Therefore, identification of significant factors affecting the selection of procurement system and development of model for a realistic selection process is essential to the success of any type of project. In this context, the primary aim of this study on construction procurement was to investigate factors affecting the selection of procurement system and development of Decision Support Model for construction clients/their consultants to assist them in initial decision making on procurement 
selection which is capable of increasing client's satisfaction while removing unnecessary influence of individuals involving procurement system selection on behalf of clients.

\section{Research Methodology}

The attempt to develop such a Decision Support System is based on the review of alternative approaches developed over the past decade and the current practice of procurement selection in Sri Lankan construction industry. Multi Attribute Utility Techniques (MAUT) were employed for the development of the model which is to be used as a decision making tool for best procurement system selection in construction. The use of MAUT can minimize the subjective elements that tend to predominate in the decision making process and can increase transparency (Shen et al., 1998). In this study, MAUT was used to integrate both priority ratings and the utility values derived from the respective factors. It focuses on the development of a MAUT based selection model that is construction project procurement selection specific. The model was developed using the results derived from four rounds of Delphi survey. Delphi method is a highly formalized method of communication that is designed to extract the maximum amount of unbiased information from a panel of experts (Chan et.al., 2001). Therefore, it was considered appropriate to adopt the Delphi technique which targeted to identify \& analyze the decisive factors affecting the selection of procurement systems and attain the utility values for each factor against various procurement systems. The steps involved in carrying out the study were:

(1) determination of key selection criteria at macro level;

(2) determination of wide range of procurement systems;

(3) collection of utility values for each criteria against various procurement systems; and (4) collection of selection criteria weightings. Delphi and MAUT techniques were used to facilitate a more systematic and logical approach in the selection process, hence improving objectivity and reducing subjectivity in decision making.

\section{Alternative Approaches to Procurement Selection: Literature Review}

According to Masterman (1992), the practice of procurement selection is rather unstructured and ad hoc. One of the pertinent questions is that, in reality does the client or his representative use a structured model for procurement selection? Several procurement selection systems have been developed to help the clients to choose the most appropriate procurement systems, ranging from simple rating systems (Franks, 1990) to highly complex systems such as multi-attribute and matrix based systems (Skitmore and Marsden, 1988; Liu, 1994). However, in all of the models there is always a need to input the specific characteristics of client, project and possibly procurement process features that are subjective based on the point of view of the user. Further, it is strategically important to make sure that the selection is done systematically and in a closely controlled manner. Table 1 summarizes the review of alternative approaches to procurement selection and their basic methodology developed over the past two decades.

Among these models, Multi Attribute Utility Technique (MAUT) received the greatest attention. Chang and Ive (2002) discussed some of the inherent problems of using MAUT for procurement selection. One of the strongest criticisms was the selection of procurement variables. The other is the utility value developed through opinions of industry experts. Particularly they are critical about the subjective nature of assigning values to procurement selection parameters to obtain mean utility values. The main difficulties common to these alternative approaches developed during the past two decades could be pointed out as follows;

- All models failed to include some important factors based on main criteria for the selection of most appropriate procurement systems. Some of the models only include limited number of criteria based on client's requirements and certain models consider limited number of client's requirements and project characteristics.

- The available procurement systems included in the existing models are limited. Certain models seem to ignore the variants of the main categories of procurement systems. Some of the other models include limited number of variants of main categories.

- Some models are conditional and cannot be used by any client (Alhzmi and McCaffer, 2000).

- Some of the models require the use of advanced mathematical techniques, which are considered to be time consuming (Alhzmi and Mccaffer, 2000).

- $\quad$ Some of the models require the use of advanced computer packages, which can not be used by all the clients/consultants.

- A number of existing models adopt a primitive approach to the selection process and limit the number of options to be considered (Alhzmi and McCaffer, 2000). 
Table 1: Review of alternative approaches to procurement selection

\begin{tabular}{|c|c|c|}
\hline Author & Year & Description of Alternative Approaches \\
\hline NEDO & 1985 & Rating system using a client's priority for nine key areas \\
\hline $\begin{array}{l}\text { Skitmore and } \\
\text { Marsden }\end{array}$ & 1988 & $\begin{array}{l}\text { Two systems: a multi-attribute model based on the NEDO model with a rating } \\
\text { system and weighting of client priorities; and a discriminate analysis technique } \\
\text { utilizing variances in procurement characteristics under certain criteria. }\end{array}$ \\
\hline Brandon et al. & 1988 & $\begin{array}{l}\text { A computer expert system called ELSIE, which determined suitable procurement } \\
\text { systems, based on project characteristics and client requirements. }\end{array}$ \\
\hline Franks & 1990 & Simple rating system based on client's performance requirements. \\
\hline Singh & 1990 & $\begin{array}{l}\text { Two systems: a multi-attribute model based on the NEDO model with a rating } \\
\text { system and weighting of client priorities; and a discriminate analysis technique } \\
\text { utilizing variances in procurement characteristics under certain criteria. }\end{array}$ \\
\hline Bennett and Grice & 1990 & $\begin{array}{l}\text { System based on the NEDO and Skitmore and Marsden models and allows } \\
\text { clients to weight specific criteria multiplied by set utility ratings for the various } \\
\text { systems. }\end{array}$ \\
\hline Mohsini & 1993 & $\begin{array}{l}\text { A knowledge-based expert system (project acquisition strategy consultant), which } \\
\text { starts by establishing the project characteristics and the client's posture towards } \\
\text { project control and risk taking }\end{array}$ \\
\hline Gordon & 1994 & $\begin{array}{l}\text { Three drivers of project, owner, and market as well as a riskallocation analysis } \\
\text { and a commodity versus service analysis, to guide the clients into using an } \\
\text { appropriate procurement method. }\end{array}$ \\
\hline Liu & 1994 & $\begin{array}{l}\text { An organizational behaviour-based model utilizing an act-to-outcome process } \\
\text { governed by organizational goals, which in turn are subject to moderators, which } \\
\text { determine goal/performance relationship. }\end{array}$ \\
\hline Chan et al. & 1994 & $\begin{array}{l}\text { A model utilizing the Bennett and Grice model, but uses a different procurement } \\
\text { category developed for the Australian construction industry. }\end{array}$ \\
\hline Love & 1996 & A systematic first-principle analysis \\
\hline Love et al. & 1998 & $\begin{array}{l}\text { A procurement path decision chart, which allows clients to weight a simple set of } \\
\text { criteria based on clients' requirements multiplied by set utility ratings for the } \\
\text { various systems. }\end{array}$ \\
\hline Dell'Isola et al. & 1998 & $\begin{array}{l}\text { Decision matrix-based model that rates the performance of each procurement } \\
\text { system for selected issues and their relative importance on a client/project profile. }\end{array}$ \\
\hline $\begin{array}{l}\text { Ambrose and } \\
\text { Tucker }\end{array}$ & 1999 & $\begin{array}{l}\text { A three-dimensional interaction matrix that provides a procedure to evaluate the } \\
\text { appropriateness of a procurement system for a particular project and the needs } \\
\text { of the client. }\end{array}$ \\
\hline $\begin{array}{l}\text { Alhazmi and } \\
\text { McCaffer }\end{array}$ & 2000 & $\begin{array}{l}\text { A Project procurement system selection model which is an integration of Parker's } \\
\text { judging alternative technique of Value Engineering and Analytical Hierarchy } \\
\text { Process (AHP) }\end{array}$ \\
\hline Chan et al. & 2001 & $\begin{array}{l}\text { A multi attribute model, which allows clients to weigh a set of exclusive criteria } \\
\text { multiplied by set utility ratings for limited number of procurement systems. }\end{array}$ \\
\hline Cheung et al. & 2001 & $\begin{array}{l}\text { A procurement selection model based on multi-attribute utility technology with the } \\
\text { use of Analytical Hierarchy Process (AHP) to determine the importance } \\
\text { weightings of the selection criteria basedon client requirements. }\end{array}$ \\
\hline
\end{tabular}

Against this background, the present study has attempted to develop a selection model by which most of the difficulties pertaining to the existing models could be overcome by the end user.

\section{Formation of Procurement Selection Criteria}

A set of exclusive selection criteria at macro level has been established from this study based on the Sri Lankan context. Delphi technique was adopted to ascertain the set of selection criteria and the utility values for each selection criteria against a wide range of various procurement systems. Altogether, four rounds of Delphi survey were conducted. The Delphi technique has demonstrated to be powerful and appropriate technique to achieve these tasks by deriving objective opinions in a rather subjective area. The synthesis of the outcomes of the previous studies related to procurement selection seems to neglect some of the significant factors from key selection criteria. Therefore, this study has focused on the selection criteria in terms of client requirements, project characteristics, and external environment, thus ensuring that the selection criteria have been focused at macro level. The results of factor analysis revealed nine significant factors from client requirements,six factors from the project 
Table 2: Significant selection criteria and their level of Significance Selection Criteria

\begin{tabular}{|c|c|c|}
\hline \multicolumn{2}{|r|}{ Selection Criteria } & Significance level \\
\hline \multirow{9}{*}{ 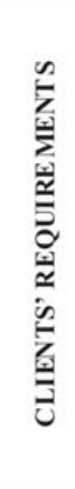 } & Risk management & 0.0000 \\
\hline & Time availability and predictability & 0.0000 \\
\hline & Price certainty & 0.0000 \\
\hline & Price competition & 0.0000 \\
\hline & Accountability & 0.0000 \\
\hline & Flexibility for changes & 0.0000 \\
\hline & Quality of work & 0.0000 \\
\hline & Responsibility and Parties involvement & 0.0399 \\
\hline & Familiarity & 0.0000 \\
\hline \multirow{6}{*}{ 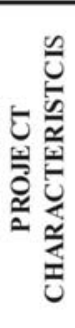 } & Project cost and Funding method & 0.0000 \\
\hline & Project complexity & 0.0000 \\
\hline & Project type & 0.0000 \\
\hline & Time constrains & 0.0000 \\
\hline & Degree of flexibility & 0.0000 \\
\hline & Payment modality & 0.0000 \\
\hline \multirow{5}{*}{ 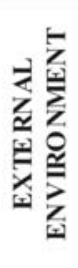 } & Market competition & 0.0000 \\
\hline & Economic condition and the fiscal policy & 0.0120 \\
\hline & Technology & 0.0000 \\
\hline & Socio cultural suitability & 0.0210 \\
\hline & Regulatory environment & 0.0000 \\
\hline
\end{tabular}

characteristics and five factors from the external environment. Each factor derived from factor analysis was carried to the third and fourth rounds which targeted to attain the utility values for each significant factor against various procurement systems. Table 2 shows the final set of exclusive selection criteria and their level of significance derived from the fourth round of Delphi.

The synthesis of the survey results revealed that all the factors have remarkable influence on the selection process and factors from client requirements and project characteristics significantly influence the selection compared to external environmental factors. Based on the decisive factors identified and utility values derived from the fourth round of Delphi, a Multi Attribute Utility Model was developed and it was enhanced into a Decision Support System.

\section{Decision Support System (DSS)}

Main objective of designing such a DSS is to assist a user-friendly environment for intelligent and informed decision making for construction procurement selection. Additionally, the DSS facilitates the following:

- Ensures systematic and consistent approach for procurement selection through the application of relevant research methods
- Assists construction clients in the initial decision on making an appropriate procurement selection for any kind of building project.

- Provides better understanding on selection criteria which influence the procurement selection and various types of traditional as well as alternative construction procurement systems in practice.

- Provides report on ranked list of procurement systems

The model was designed for construction clients and/ or their consultants/principal advisers, particularly those who use an unrealistic method to select the procurement system and are responsible for the selection process. Primarily, this model guides how to select an most favorable procurement system for a particular type of building project. This model not only considers the requirements of clients and project's profile but also the impact of external environment on procurement selection. In this way, it will be possible to ensure that the project is procured in an efficient and effective way that adds value for the client.

\section{Model Development}

Development of the model consists of two main phases: Design phase and Development phase. Designing phase of the model was further considered in two processes: 
Conceptual designing and Information modeling. Conceptual design demonstrates the principles of the model while information model deals with the contents of the model. Conceptual design illustrates basic concepts behind procurement selection, which is based on secondary data collected through literature and results from Delphi survey carried out in four rounds. Figure 1 illustrates detailed design of conceptual framework for project procurement selection model.

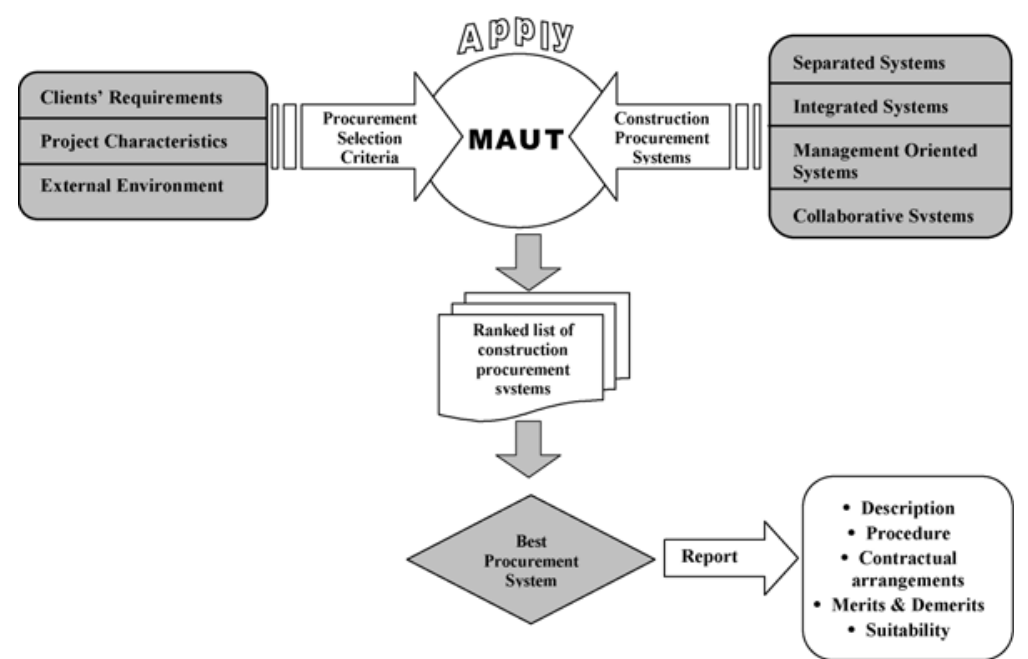

Figure 1: Detailed design of conceptual framework for the model

The steps involved in developing the contents of the model are:

(1) Determination of selection criteria;

(2) Determination of various procurement systems;

(3) Collection of utility values; and

(4) Collection of weightings for each selection criteria.

Step 1 and Step 3 were achieved using Delphi technique and the Step 4 was achieved using interviews with project's client or consultants. The clients' weights determine the relative importance of each criterion on a scale of 1-5. This relative importance score is termed as priority rating. Finally the MAUT was applied to achieve the selection procedure in a systematic and disciplined manner.

\section{The Object Oriented Information Model}

Information modeling which is the logical representation of information, simply defines procedures, which must be followed, and data required to achieve user requirements. There are two main techniques of information modeling, viz: Structured approach and Object oriented approach (Ramakrishnan and Johannes, 2004). The object oriented approach was used to develop the information model as it was developed to imitate a more natural way of defining systems than that is offered by the structured approach. This method provides greater flexibility and reusability, furnishing a components based programming framework
(Rumbaugh et al., 1991; Booch, 1991). The Unified Modeling Language (Beaumont, 2005; Collins, 2005) standard notations were used to express the content of the information model generated. The object-oriented model developed for the procurement selection is depicted at Figure 2.

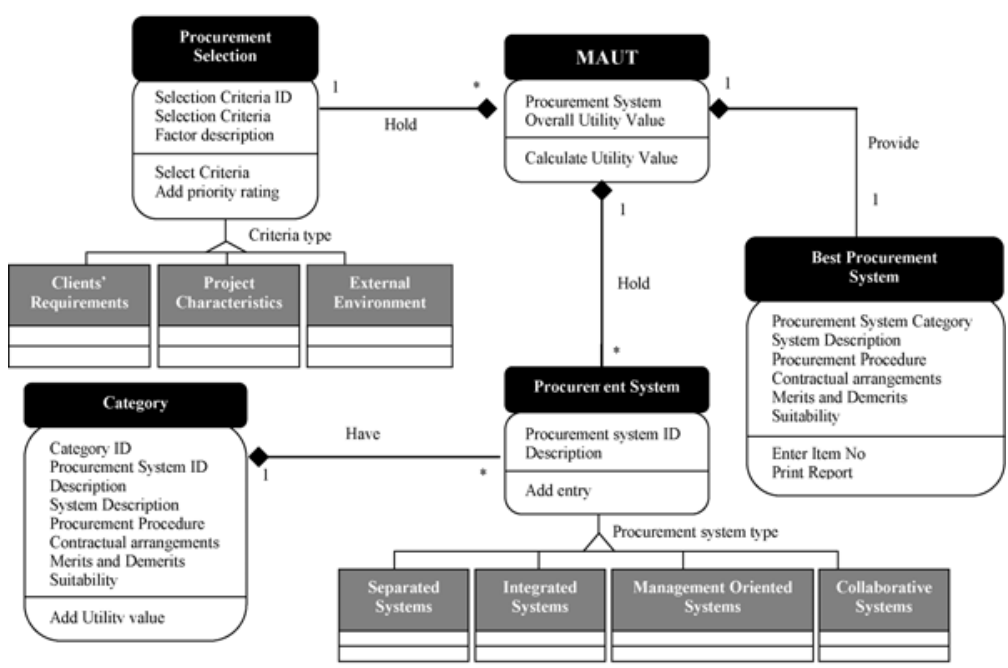

Figure 2: Object oriented model for procurement selection

Object models symbolize the entities and their relationships. Model consists of five classes as follows;

1. Procurement selection class (contains selection criteria ID and selection criteria)

2. MAUT class (contains procurement system ID and overall utility value)

3. Procurement system class (contains procurement system ID and description)

4. Category class (contains category ID, procurement system ID, description, system description, procurement procedure, contractual arrangements, merits \& demerits and suitability),

5. Best procurement system class (contains procurement system category, system description, procurement procedure, contractual arrangements, merits \& demerits and suitability).

The methods "Add entry", "Add priority rating", "Select criteria", "Add utility value", "Print report" and "Calculate overall utility value" are the tasks or process carried out by the system.

\section{Application of MAUT}

MAUT is a methodology that may be used as a tool for measuring objectivity in an otherwise subjective area (Fellows et al., 1983). Procurement system is the overall managerial approach by which a client commissions and obtains a building. MAUT is an attempt to apply a quantitative decision method to the context of construction procurement route selection, so as to provide clear normative advice for improving the quality of clients' decision-making (Skitmore and Marsden, 1988; Chan, 1995; Love et al., 1998; Ambrose and 
Tucker, 2000). Therefore, Multi-Attribute Technique was considered to be the foremost technique appropriate for examining the main selection criteria \& their variables and the preferences of experts' weights for each system in the most objective way. In this study, MAUT is used to integrate both priority ratings and the utility values derived from the respective factors. An example for the application of MAUT for the project procurement selection is portrayed in Table 3 (A part of the model).

\section{Model evaluation}

Next stage was the evaluation of the practical use of the model to ensure the consistency and soundness of the model. Multiple case studies in a sampling of 44 building projects and unstructured interviews with selected clients/consultants from the industry were conducted to test the practical use of the model. These case studies demonstrate how this model could be applied in reality to come up with the best procurement systems for various types of building projects. Altogether, 44 case studies on actual projects were carried out to validate the contents and evaluate the applicability of the model. The results of the model were compared with the actual procurement system adopted to each project selected. The actual procurement systems used for selected projects include thirty seven 'Traditional Measure and Pay', one 'Traditional Lump Sum', five 'Design and Build' and one 'Turn key', suggesting a seemingly dominant use of the Traditional Measure and Pay system. Out of the 44 case studies conducted, there were 31 (70\%) matching results and $13(30 \%)$ non-matching results observed. Even though the selection practice of construction procurement is rather unstructured and ad hoc, the results revealed from the model demonstrates that $70 \%$ of the results tally with the procurement system already adopted. Therefore, it can be stated that the applicability of the model is efficient in the Sri Lankan industry.

\section{Development of DSS}

DSS development based on evaluated model consisted of three main phases: Database development, System interface development and System testing. These are explained in detail in the following sections.

\section{Database development}

A database is a collection of data, which provides meaningful information. It facilitates data integrity, consistency and independence and reduces redundancy. DSS database uses structure of relational model as it provides ability for end users to create and change the records in the database in a user-friendly process (Lonnie and David, 1997). Moreover, many standard software packages facilitate development of relational databases. Relationships among entities of DSS are illustrated in the object oriented model given in Figure 2. There are various software programmes available for database development such as Oracle, Microsoft SQL and IBM ${ }^{\mathrm{TM}}$ DB compatible with Java development. Microsoft ${ }^{\mathrm{TM}}$ Access 2000 was used for the development of database in this DSS.

\section{System interfaces}

System interfaces were developed using Java programming language, which incorporates certain features such as polymorphism and inheritance, illustrated at object oriented framework for procurement selection. Java development environment offers certain

Table 3: Illustration for the use of Multi Attribute Utility Model

\begin{tabular}{|c|c|c|c|c|c|c|c|c|c|c|c|c|c|c|}
\hline & \multirow{3}{*}{ SELECTION CRITERIA } & \multirow{3}{*}{$\begin{array}{c}\text { Client's } \\
\text { Priority } \\
\text { rating }\end{array}$} & \multicolumn{12}{|c|}{ Utility values } \\
\hline & & & \multicolumn{3}{|c|}{ Separated } & \multicolumn{5}{|c|}{ Integrated } & \multicolumn{2}{|c|}{$\begin{array}{c}\text { Management } \\
\text { Oriented }\end{array}$} & \multicolumn{2}{|c|}{ Collaborative } \\
\hline & & & M \& P & LS & $\mathrm{PC}$ & D \& B & PD & TK & $D \& C$ & PFI & $\mathrm{CM}$ & MC & Part & JV \\
\hline \multicolumn{15}{|c|}{ Clients' Requirements } \\
\hline \multirow[t]{2}{*}{1} & Risk Management & 5 & 62.83 & 81.74 & 55.06 & 77.83 & 69.57 & 81.43 & 57.83 & 57.17 & 61.09 & 63.48 & 71.30 & 69.57 \\
\hline & & & $314.15^{*}$ & 408.7 & 275.3 & 389.15 & 347.85 & 407.15 & 289.15 & 285.85 & 305.45 & 317.40 & 356.50 & 347.85 \\
\hline \multirow[t]{2}{*}{2} & $\begin{array}{l}\text { Time Availability \& } \\
\text { Predictability }\end{array}$ & 5 & 58.83 & 60.00 & 65.00 & 82.17 & 81.30 & 84.13 & 61.96 & 54.35 & 63.09 & 63.50 & 57.78 & 56.52 \\
\hline & & & 294.15 & 300.00 & 325.00 & 410.85 & 406.50 & 420.65 & 309.8 & 271.75 & 315.45 & 317.50 & 288.90 & 282.60 \\
\hline \multirow{2}{*}{3} & Price Certainty & 5 & 66.41 & 95.43 & 43.70 & 82.83 & 76.71 & 86.96 & 58.48 & 54.35 & 60.43 & 58.57 & 50.57 & 52.74 \\
\hline & & & 332.05 & 477.15 & 218.50 & 414.15 & 383.55 & 434.80 & 292.40 & 271.75 & 302.15 & 292.85 & 252.85 & 263.70 \\
\hline \multirow[t]{2}{*}{4} & Price Competition & 3 & 93.26 & 82.83 & 69.57 & 64.57 & 62.35 & 51.74 & 49.45 & 42.96 & 64.13 & 59.57 & 42.61 & 58.04 \\
\hline & & & 279.78 & 248.49 & 208.71 & 193.71 & 187.05 & 155.22 & 148.35 & 128.88 & 192.39 & 178.71 & 127.83 & 174.12 \\
\hline \multirow[t]{2}{*}{5} & Accountability & 2 & 89.13 & 76.30 & 84.57 & 57.17 & 56.52 & 51.09 & 57.7 & 54.48 & 72.98 & 70.13 & 69.78 & 70.26 \\
\hline & & & 178.26 & 152.6 & 169.14 & 114.34 & 113.04 & 102.18 & 115.4 & 108.96 & 145.96 & 140.26 & 139.56 & 140.52 \\
\hline \multirow[t]{2}{*}{6} & Flexibility for Changes & 4 & 95.43 & 38.70 & 78.70 & 51.96 & 50.87 & 38.48 & 56.3 & 51.30 & 71.70 & 68.48 & 70.22 & 66.04 \\
\hline & & & 381.72 & 154.80 & 314.80 & 207.84 & 203.48 & 153.92 & 225.20 & 205.20 & 286.80 & 273.92 & 280.88 & 264.16 \\
\hline \multirow[t]{2}{*}{7} & Quality of Work & 5 & 77.61 & 72.17 & 67.00 & 67.78 & 64.57 & 59.70 & 62.74 & 57.57 & 78.35 & 78.35 & 75.82 & 76.30 \\
\hline & & & 388.05 & 360.85 & 335.00 & 338.90 & 322.85 & 298.50 & 313.70 & 287.85 & 391.75 & 391.75 & 379.10 & 381.50 \\
\hline \multirow[t]{2}{*}{8} & $\begin{array}{l}\text { Responsibility \& Parties } \\
\text { Involvement }\end{array}$ & 5 & 67.87 & 70.13 & 60.43 & 72.09 & 67.39 & 74.35 & 68.91 & 68.08 & 70.57 & 69.74 & 69.35 & 71.09 \\
\hline & & & 339.35 & 350.65 & 302.15 & 360.45 & 336.95 & 371.75 & 344.55 & 340.4 & 352.85 & 348.7 & 346.75 & 355.45 \\
\hline \multirow[t]{2}{*}{9} & Familiarity & 3 & 97.83 & 90.00 & 73.17 & 72.61 & 57.61 & 59.13 & 54.83 & 47.10 & 43.04 & 42.09 & 33.48 & 36.74 \\
\hline & & & 293.49 & 270.00 & 219.51 & 217.83 & 172.83 & 177.39 & 164.49 & 141.3 & 129.12 & 126.27 & 100.44 & 110.22 \\
\hline
\end{tabular}


benefits for this kind of purposes such as faster development, reusability, increased quality, modular architecture, better mapping of problem domain and client/ server applications (Adhikari, 1995; Taylor, 1990).

There are four user interfaces including main and sub menu that work with DSS, details of which are discussed below:

1. Main menu

2. Construction procurement selection criteria and the priority level entry form

3. Ranked list of procurement systems

4. Report on selected procurement system

\section{Main menu}

This is the pathway to the DSS. It consists of five main menus and certain main menus possess some sub menus. Main menu of DSS comprises certain components as depicted in Figure 3.

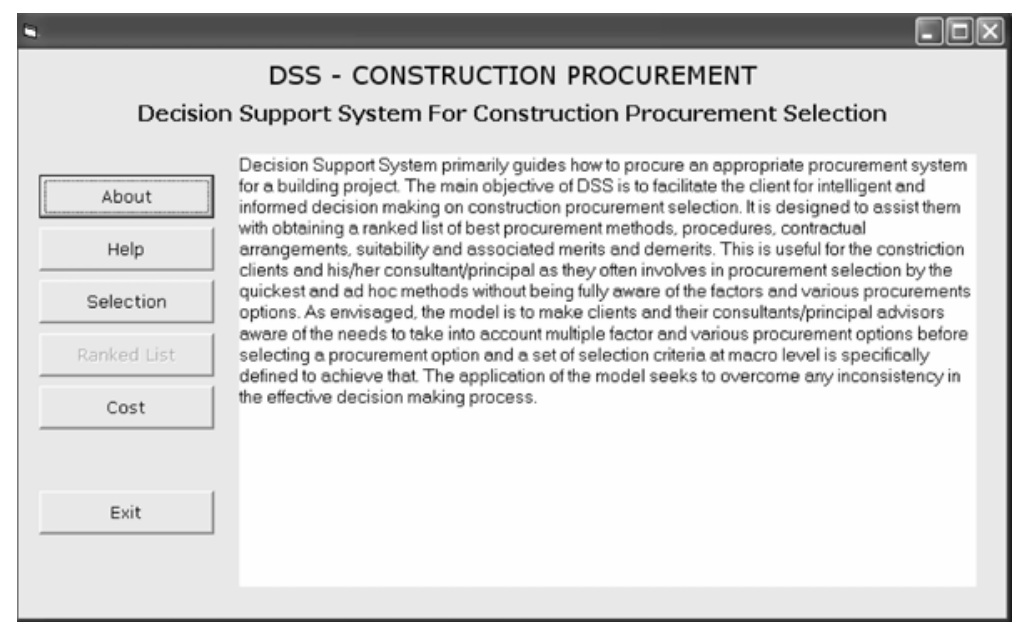

Figure 3: Main Menu of the DSS

This illustrates five options:

- $\quad$ About : Provides introduction to DSS and its special features

- Help : Guides the end user, how to use the model - Selection: This is the main component of DSS, which enables the end user to consider important selection factors at macro level and to give the priority rating according to the client's specific requirements, project characteristics and influence of external environment.

- $\quad$ Ranked list: Provides a ranked list of procurement systems, which assists the end user in initial decision making to select appropriate procurement options for his/her project.

- $\quad$ Cost : Provides understanding of true cost saving in each procurement option

- $\quad$ Exit: Allows exit from the system.

\section{Construction procurement selection criteria and the priority level entry form}

This form (Figure 4) facilitates the end user to provide inputs to the system. This form is used to consider the selection criteria and enter priority ratings for individual projects. The main components of the input screen are clearly explained below.

\section{A. Considers key selection criteria eg.: Client's requirements, Project characteristics, External Environment}

B. Determines the factors which influence the selection of procurement for the particular project.

C. Provides description for each selection factor

D. Assigns priority rating to each factor (weightings 1-5)

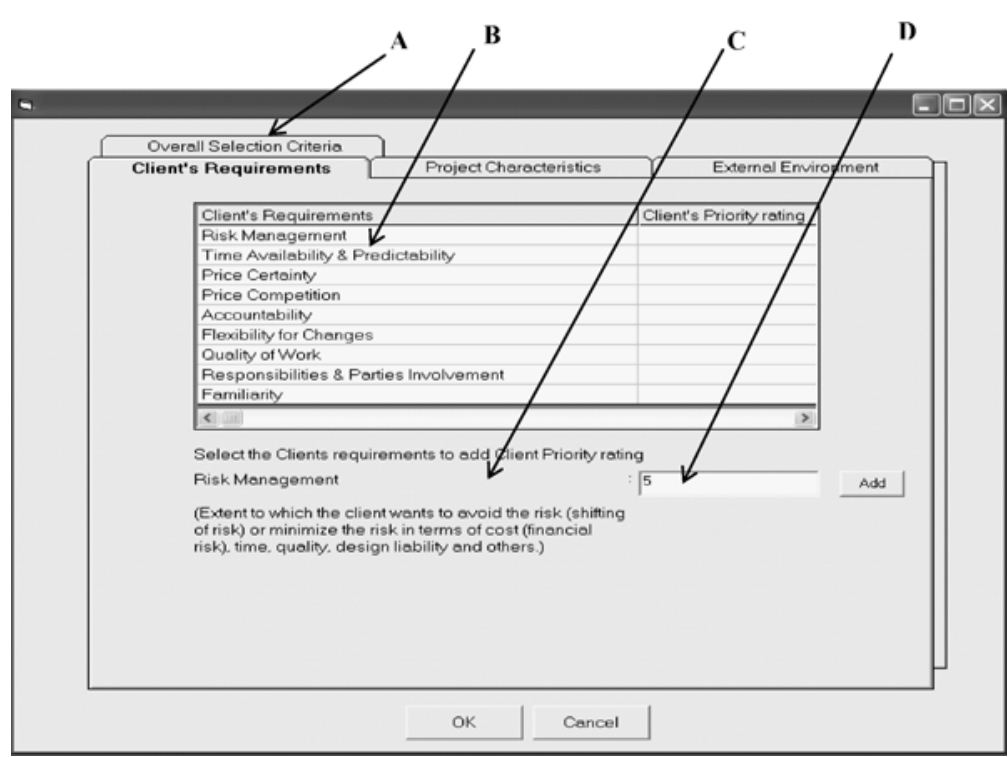

Figure 4: Priority level entry form

\section{Ranked list of procurement systems}

This form (Figure 5) provides ranked list of best procurement systems for given project.

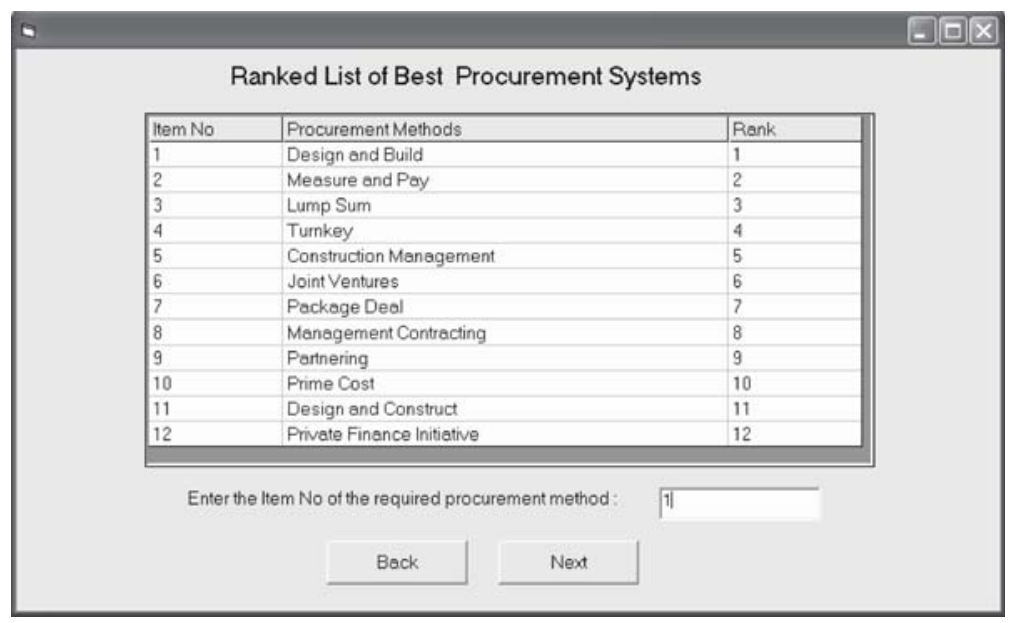

Figure 5: Ranked list of procurement systems 
This facilitates the selection of an appropriate procurement system from the ranked list of procurement options. The end user gets the idea of suitable procurement system according to their order of frequency.

\section{Report on selected procurement system}

This form provides on screen or printed form of report on selected procurement system. The report consists of the following;

- Description for the system

- Procedures associated with the respective systems

- Contractual arrangements of the system (Relationship between parties involved)

- Merits and demerits of the system

- List of suitable projects which can be procured through the selected procurement system (Examples from industry practice)

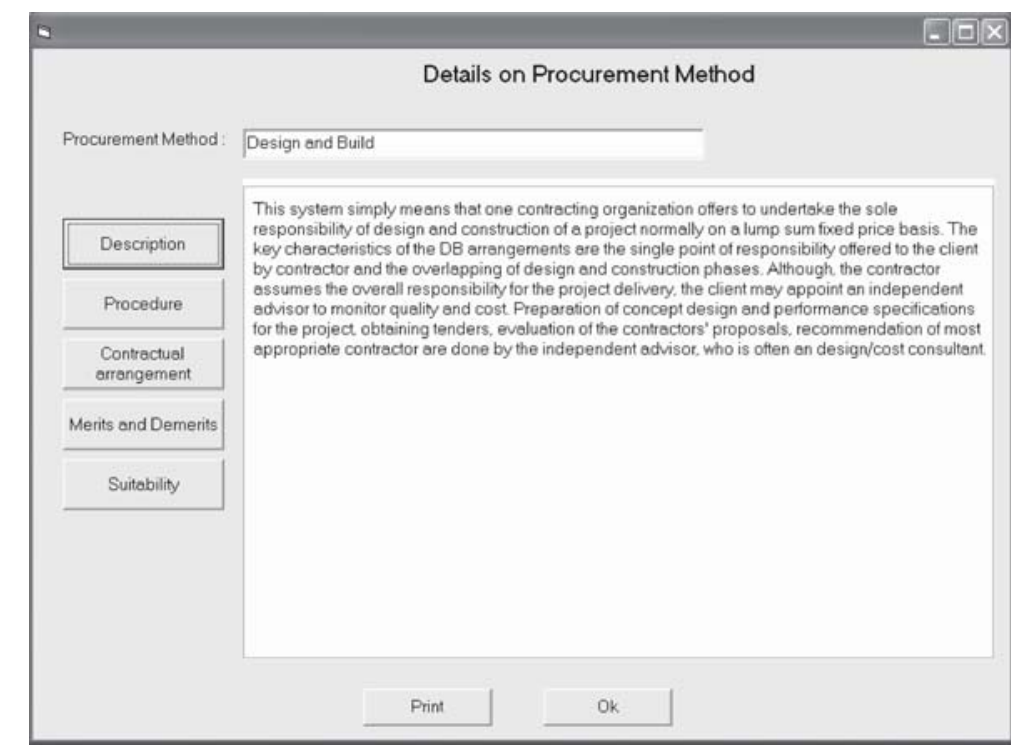

Figure 6: Report on selected procurement method Description

\begin{tabular}{|c|c|c|}
\hline 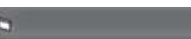 & & $-\sigma x$ \\
\hline \multicolumn{3}{|c|}{ Details on Procurement Method } \\
\hline \multirow[t]{2}{*}{ Procurement Method: } & \multicolumn{2}{|l|}{ Design and Build } \\
\hline & \multicolumn{2}{|l|}{ Merits } \\
\hline Description & \\
\hline Procedure & \multicolumn{2}{|l|}{ Fixed priced bids are used } \\
\hline & \multicolumn{2}{|l|}{ Design and construction ate integrated } \\
\hline Contractual & \multicolumn{2}{|l|}{ Total duration is reduced } \\
\hline & \multicolumn{2}{|l|}{ Time and cost overruns are less likely to occur } \\
\hline Merits and Demerits & \multicolumn{2}{|l|}{ Client's imvolvement con be minimized } \\
\hline & \multicolumn{2}{|l|}{ Demerits } \\
\hline Suitability & \multicolumn{2}{|l|}{ Lack of independent ent professional advice to client } \\
\hline & \\
\hline & \multicolumn{2}{|l|}{ Requires a detailed client's brief } \\
\hline & \multicolumn{2}{|l|}{ Flexibility to changes is less and expensive } \\
\hline & \multicolumn{2}{|l|}{ Client's control of quality and functionality is minimized } \\
\hline & \multicolumn{2}{|l|}{ Tender price can be expensive to bidder } \\
\hline & Print & \\
\hline
\end{tabular}

Figure 7: Report on selected procurement method Merits and Demerits
The main objective of this report is to provide more information on the selected procurement method, in particular to the clients who lack knowledge in alternative procurement systems. Above Figure 6 and Figure 7 illustrate details on the 'Design and Build' procurement system. They depict the description of the system and merits \& demerits of such system respectively.

\section{System testing}

The purpose of the system testing is to validate the accuracy and applicability of the developed system. The DSS prototype was tested in two stages by using sample data and actual data. In the first stage, it was tested by using hypothetical cases to validate the development process. Then the model was tested with actual scenarios developed by results extracted from the industry-based case studies to verify accuracy. If the DSS to be implemented as an industry software, it should be developed further by the use of same software programmes or any other to make it a fully functional software. Since at present it is a prototype in which most interfaces are saddled with default outputs.

\section{Evaluation of DSS: review of expert opinion survey}

The objective of the expert opinion survey was to verify the acceptability and efficiency of the model and DSS through experts' opinion. The survey was conducted among industry experts who posses experience in procurement and those who are familiar with IT applications. Information was elicited through semi structured interviews, demonstrations, and discussions as such methods provide openness to an interviewee (clients/consultants/principal advisers) to express genuine opinion, feeling at ease. Table 4 presents the review of the results of expert opinion survey.

Table 4: Review of expert opinion survey

\begin{tabular}{|l|l|}
\hline \multicolumn{2}{|c|}{ DSS for Construction Procurement Selection } \\
\hline Criteria & \multicolumn{1}{c|}{ Expert opinion } \\
\hline General view & $\begin{array}{l}\text { - Since the procurement selection practice is rather un-structured and ad } \\
\text { hoc, development of a systematic and consistent model is well appreciated } \\
\text { - It will assist building clients in initial decision making } \\
\text { - It is construction procurement specific, therefore, will perform its superior } \\
\text { function to industry practice. } \\
\text { - The 'help' menu of the system assists clients who are not experienced in } \\
\text { IT, how to use this system }\end{array}$ \\
\hline Shortcomings & $\begin{array}{l}\text { - Clients who are not familiar with IT may face difficulties in making use of } \\
\text { this model. } \\
\text { - It does not give any indication on cost aspects of procurement systems. }\end{array}$ \\
\hline Suggestions & $\begin{array}{l}\text { - Model should be flexible enough to include the further selection criteria } \\
\text { and new procurement options to keep up with new developments in } \\
\text { procurement. } \\
\text { - Improve prototype to fully functional software. }\end{array}$ \\
\hline Delphi & $\begin{array}{l}\text { Application of Research Methodology } \\
\text { - Delphi is suitable techniques to achieve the defined objectives of the } \\
\text { author. }\end{array}$ \\
\hline MAUT & $\begin{array}{l}\text { Since procurement system is overall managerial approach, MAUT is a } \\
\text { relevant tool to make rather subjective matters of management into } \\
\text { objective matters. }\end{array}$ \\
\hline
\end{tabular}

The author in consideration of certain views expressed by such experts makes following comments. 
- Model will be updated at regular time intervals to keep it up-to-date to overcome tendencies of is olation.

- Although public sectors organizations cannot adopt this model due to policies imposed on procurement by the government, still it can be used as a base to improve or modify procurement polices.

- Model was designed, evaluated and developed based on results obtained by surveys and case studies conducted in actual construction projects. Therefore, it is more suitable for construction clients or their consultants/principal advisors.

- Although development of model to fully functional software is not within the scope of this research, enhancing the model up to that extent will provide more benefits to construction industry.

- The cost aspects of selected procurement system are not within the scope of the research due to time limitations.

\section{Limitations of DSS}

This DSS is subjected to following constraints and limitations:

1. Model contents restricted to nineteen selection criteria and twelve types of procurement systems, which were identified through the comprehensive Delphi survey conducted among experts in construction industry.

2. Model development and evaluation is restricted to buildings projects.

3. Model development is restricted to a scaleable prototype, which is only used for demonstration purposes of a real system. Therefore, most interfaces are saddle with default outputs.

4. Model provides reports on best procurement systems, but there is no flexibility for a user to query reports, as they would prefer.

5. The cost aspects of the selected procurement systems have not been incorporated in this model.

\section{Conclusions}

A Systematic and realistic approach for the selection of most suitable procurement system is critical to the success of any project, thus to achieve the clients' ultimate goals. This study has adopted the Delphi technique together with MAUT to develop a multiple decisive factor model for the selection of best procurement system in construction. These two techniques were used to facilitate a more systematic and consistent approach in the selection process, hence improving objectivity and reducing subjectivity in decision making. The Delphi technique was used to derive the utility values for each factor against various procurement systems. The special feature of this model is the inclusion of a set of selection criteria at macro level. The final selection model consists of a set of selection criteria in terms of clients' requirements, project characteristics \& external environment, a set of utility values for each selection criteria and a broader categorization of procurement systems. This is useful for the construction clients and their consultants who often involve in procurement selection by the quickest and ad hoc methods without being fully aware of the factors and various procurements options. As envisaged, the model will make clients and their consultants/principal advisers aware of the needs to take into account multiple factors and various procurement options before selecting a procurement option and a set of selection criteria at macro level is specifically defined to achieve that. The application of the model seeks to overcome any inconsistency in the effective decision making process due to the influence of individuals and other external factors and has the potential to assist the clients/consultants. The implementation of this model to aid procurement selection is advocated to place the clients in best possible position to select correct method of procurement for their projects at a particular circumstance.

Finally, the evaluated model was successfully enhanced into a Decision Support System (DSS) which allows users to make intelligent and informed decisions on selection of procurement routes for various building projects. DSS development herein is restricted to a scaleable prototype, which is only used for demonstration purposes of a real system. Evaluated model was enhanced to DSS with integration of new technology in two development phases which includes database and interfaces development. The expert opinion survey, which targeted to validate the model, revealed that the DSS provides assistance in initial decision-making on project procurement selection to all types of building clients of the construction industry. Since this DSS is a prototype, most interfaces are saddled with default outputs. DSS can be effectively used by the industry clients only through further development of a fully functional system.

\section{References}

Adhikari, R. (1995) Adopting OO Languages? Check Your Mindset at the Door, Software Magazine, November, 49-59.

Alhazmi, T. and McCaffer, R. (2000) Project procurement systems selection model. Journal of Construction Engineering and Management, 126(3), 176 - 183. 
Ambrose, M.D. and Tucker, S.N. (1999) Matching a procurement system to client and project needs: a procurement system evaluator, In : Proceedings Customer Satisfaction: A Focus for Research and Practice in Construction, P.A. Bowen and R.D. Hindle (eds), Cape Town, South Africa, University of Cape Town, 280-288.

Bennett, J. and Grice, A. (1990) in Brandon, P.S. (Ed.), Procurement Systems for Building, Quantity Surveying Techniques, New Directions, BSP Professional Books, Oxford.

Booch, G. (1991) Object oriented design with applications, The Benjamin Publishing Company, Redwood City, California.

Brandon, P. S., Basden, A., Hamilton, I. W. and Stockley, J. E. (1988) Application of Expert Systems to Quantity Surveying, Royal Institution of Chartered Surveyors, London.

Chan, A. P. C., Tam, C. M., Lam, K. C., and So, A. T. P. (1994) A multi-attribute approach for procurement selection: an Australian model. In: Proceedings of the Tenth Annual Conference of the Association of Researchers in Construction Management, Loughborough University of Technology, September, 621-30.

Chan, A. P. C. (1995) Towards an expert system on project procurement. Journal of Construction Procurement, 1(2), 111-23.

Chan, A.P.C., Yung, E.H.K., Lam, P.T.I., Tam, C.M., and Cheung, S.O. (2001) Application of Delphi method in selection of procurement systems for construction projects, Construction Management and Economics, 19, 699-718.

Chang, C.Y. and Ive, G. (2002) Rethinking the Multi Attribute Utility Approach based procurement route selection technique, Construction Management and Economics, 20, 275-84.

Cheung, S., Lam, T., Leung, M. and Wan, Y., (2001) An analytical hierarchy process based procurement selection method, Construction Management and Economics,19, 427-437.

Collins, M. (2005) 'Object Oriented Analysis and Design Using UML', Ratio Group Ltd. Available from: www.ratio.co.uk [Accessed 12 October 2006].

Dell'Isola, M. D., Licameli, J. P. and Arnold, C. (1998) How to form a decision matrix for selecting a project delivery system. Design-Build Strategies, 4, 2.
Egan, J. (1998) Rethinking Construction, Department of the Environment, Transport and the Regions, HMSO, London.

Fellows, R. F., Langford, D., Newcombe, R. and Urry, S. (1983) Construction Management in Practice, Longman, New York.

Franks, J. (1990) Building Procurement Systems, Chartered Institute of Building, Englemere, Kings Ride, Ascot.

Gordon, C.M. (1994) Choosing appropriate construction contracting method, Journal of Construction Engineering and Management, ASCE, 120 (1), 196-210.

Latham, M., (1994), Construction the Team: Final Report of the Joint Government / Industry Review of Procurement and Contractual Arrangements in U. K. Construction Industry, HMSO, London.

Liu, A.M.M. (1994) From act to outcome: a cognitive model of construction procurement", In: Rowlinson, S. (Ed.), CIB W92 Proceedings: East Meets West Procurement Systems Symposium, 4-7 December, Hong Kong, 16978.

Lonnie E.M. \& David M.B. (1997) Microsoft Office $97,2^{\text {nd }}$ ed., BPB publications, New Delhi.

Love, P.E.D. (1996) Fast building: an Australian perspective, In: Proceedings of CIB-W92 Procurement Systems Symposium, North Meets South, Developing Ideas, Durban, South Africa, 14- 17 January, pp. 329- 43.

Love, P.E.D., Skitmore, M. and Earl, G. (1998) Selecting a Suitable Procurement Method for a Building Project, Construction Management and Economics, 16, 221-233.

Luu, S.D.T., Ng, T., and Chen, S. (2003) Parameters governing the selection of procurement system, Engineering, Construction and Architectural Management, 10 (3), 209-218.

Masterman, J. W. E. (1992) An Introduction to Building Procurement Systems, E \& FN Spon, London.

Moshini, R.A. (1993) Knowledge-based design of project procurement process, Journal of Computing in Civil Engineering, ASCE, 7(1), 107-122.]

NEDO, (1985) Thinking about building, Report by Building, Design Partnership for National Economic Development Office, Building EDC, HMSO. 
NWPC, (1990) No Dispute: Strategies for Improvement in Australian Building and Construction Industry, National Public Works Conference, Canberra, Australia.

Ramakrishnan, R. and Johannes, G. (2004) Database Management system, $3^{\text {rd }}$ ed., McGraw-Hills, USA.

Rumbaugh, J. et al (1991) Object oriented modeling and Design, Prentice-Hall International, New Jersey, USA.

Shen, Q., Lo, K. K. and Wang, Q. (1998) Priority setting in maintenance management: a modified multi-attribute approach using analytical hierarchy process. Construction Management and Economics, 16(6), 693-702.
Shiyamini, R., Rameezdeen, R., and Amaratunga, D. (2005) Macro Analysis of Construction Procurement Trend in Sri Lanka, In: Proceedings of the 5th International Postgraduate Research Conference of the Research Institute for the Built and Human Environment, The UK, University of Salford, March, pp. 525- 536.

Singh, S. (1990) Selection of appropriate project delivery system for construction projects, In: Proceedings of CIB W-90 International Symposium on Building Economics and Construction Management, Sydney, Australia, 469- 80.

Skitmore, R.M. and Marsden, D.E. (1988) Which procurement system? Towards a universal procurement selection technique, Construction Management and Economics, 6 (1), 71-89.

Taylor, D. A. (1990) Object-Oriented Technology: A Manager's Guide, Addision-Wesely, Reading, MA. 